\title{
IN-SITU RADIOCARBON PRODUCTION BY NEUTRONS AND MUONS IN AN ANTARCTIC BLUE ICE FIELD AT SCHARFFENBERGBOTNEN: A STATUS REPORT
}

\author{
K van der Borg ${ }^{1} \bullet \mathrm{W} \mathbf{J}$ M van der Kemp • C Alderliesten • A F M de Jong • R A N Lamers • \\ Institute of Subatomic Physics, Faculty of Physics and Astronomy, Utrecht University, P.O. Box 80000, \\ 3508 TA Utrecht, The Netherlands \\ J Oerlemans $\bullet$ M Thomassen $\bullet$ R S W van de Wal \\ Institute of Marine and Atmospheric Research, Faculty of Physics and Astronomy, Utrecht University, P.O. Box 80005, \\ 3508 TA Utrecht, The Netherlands
}

\begin{abstract}
In the radiocarbon accelerator mass spectrometry $\left({ }^{14} \mathrm{C}\right.$ AMS $)$ analysis of gases obtained in a dry extraction from a 52-m Antarctic ice core, we observed ${ }^{14} \mathrm{CO}_{2}$ and ${ }^{14} \mathrm{CO}$ concentrations decreasing with depth. The concentrations are explained in terms of in-situ production by neutrons and captured muons in ablating ice. The ratio of the ${ }^{14} \mathrm{CO}_{2}$ concentration to that of ${ }^{14} \mathrm{CO}$ has been found to be constant at $1.9 \pm 0.3$. The ablation rates obtained of $42 \pm 18 \mathrm{~cm} . \mathrm{yr}^{-1}$ and $40 \pm 13 \mathrm{~cm} . \mathrm{yr}^{-1}$ for the neutron and muon components, respectively, are about three times higher than observed from stake readings. The discrepancy may point to an incomplete extraction of the dry extraction method. Using the constant ratio in ${ }^{14} \mathrm{CO}_{2}$ and ${ }^{14} \mathrm{CO}$ concentrations we correct for the in-situ component in the trapped ${ }^{14} \mathrm{CO}_{2}$ and deduce an age of 10,300 $\pm 900 \mathrm{BP}$ for the ice core.
\end{abstract}

\section{INTRODUCTION}

Blue ice fields mainly occur in Antarctica at the outer edges of the main ice sheet, where the ice flow runs up against a mountain range and local winds remove the upper ice layer. In many cases blue ice fields form stranding-areas of meteorites, which after a long burial time come to the ice surface (Cassidy et al. 1992). As the ice originates from an accumulation area, where the precipitating snow forms a firn layer and gradually transforms to ice, it brings information to the blue ice field where it crops out. In the firn-to-ice transition at about $70 \mathrm{~m}$ (Schwander and Stauffer 1984) air becomes trapped in the ice. The gases are locked in the ice through their extremely small mobility and form a wealthy archive of ancient atmospheres (Neftel et al. 1983), which bears information on climate and greenhouse gases (Jouzel et al. 1987; Raynaud et al. 1993). The special role of the trapped carbon dioxide for radiocarbon dating of ice has been recognized early (Fireman 1982; Andreé 1984).

During the transportation from accumulation to ablation, regional ice is subjected to bombardment of cosmic rays, which produce radionuclides in the ice. In-situ production in the first few meters is dominated by reactions from neutrons, in the next tens of meters by captured muons and deeper by fast muons (Lal and Peters 1967). First reports on in-situ production by muons in rock were made for ${ }^{36} \mathrm{Cl}$ by Kubik et al. (1984) and for ${ }^{10} \mathrm{Be}$ by Brown et al. (1995). Heisinger (1998) determined production rates of various radionuclides in quartz by samples irradiated by muons.

Lal et al. (1987) indicated the ability to extract accumulation and ablation rates of ice sheets from the in-situ production and used ${ }^{14} \mathrm{C}$ in determining the ablation rate of Antarctic ice (Lal et al. 1990). Lal and Jull (1994) also observed in-situ ${ }^{14} \mathrm{C}$ in the firn of accumulation areas and found a variable insitu fraction retained in the ice. The variability of the retained fraction has been attributed to erosion of the firn by variable wind ventilation in the firn (Lal et al. 2000).

In a previous study, van Roijen et al. (1996) performed ${ }^{14} \mathrm{C}$ accelerator mass spectrometry (AMS) analysis on 3- and 10-m ice cores from an Antarctic blue ice field at Scharffenbergbotnen. Ablation

${ }^{1}$ Corresponding author. Email: k.vanderborg @ phys.uu.nl.

(C) 2001 by the Arizona Board of Regents on behalf of the University of Arizona

Radiocarbon, Vol 43, Nr 2B, 2001, p 751-757

Proceedings of the 17 th International ${ }^{14} \mathrm{C}$ Conference, edited by I Carmi and E Boaretto 
rates and ages were deduced. The ratio of the ${ }^{14} \mathrm{CO}$ and ${ }^{14} \mathrm{CO}_{2}$ concentrations showed to be constant in an individual core but different among cores. In addition, the asymptotic value at $10 \mathrm{~m}$, the largest depth, could not be explained by the neutron component alone. For a further investigation of these aspects we returned to the location to take another and, ice core.

\section{METHOD}

The 52-m ice core was drilled in the ablating blue ice field at Scharffenbergbotnen, Antarctica $\left(74^{\circ} 34^{\prime} 40^{\prime \prime} \mathrm{S}, 11^{\circ} 02^{\prime} 58^{\prime \prime} \mathrm{W}\right.$, elevation $\left.1173 \mathrm{~m}\right)$ during the 1997-1998 SVEA field expedition. Ice samples of about $2 \mathrm{~kg}$ were used in a dry extraction technique in which rotating knives scrape ice in a vacuum recipient situated in a freezing box held at $-35^{\circ} \mathrm{C}$. For extraction of the carbon monoxide a carrier has been added in advance. In the extraction procedure the carbon dioxide is collected with cold traps, and the remaining carbon monoxide is oxidized to $\mathrm{CO}_{2}$ and collected subsequently. Yields were obtained from precise pressure measurement. A 95\% efficiency is obtained in this on line oxidation procedure using platinum wire at $300{ }^{\circ} \mathrm{C}$. The collected $\mathrm{CO}_{2}$ fractions are converted into graphite and prepared for ${ }^{14} \mathrm{C}$ measurement with AMS (van der Borg et al. 1987, 1997). The contamination in the total extraction procedure has been determined from blanks and admixtures of $\mathrm{CO}$ and $\mathrm{CO}_{2}$ of known activity and has been found to be $1.5 \pm 0.5 \mathrm{pMC}$.

\section{ANALYSIS AND RESULTS}

Table 1 shows details about the ice samples and depth, the gas yields, and the results of the ${ }^{14} \mathrm{C}$ analysis. The mean value of the air yields from the ice samples is $108 \mathrm{~mL} / \mathrm{kg}$, which is in agreement with values earlier obtained by van Roijen (1995). The $\mathrm{CO}_{2}$ concentrations are close to modern values in the surface samples. The average concentration of the other samples is about $300 \mathrm{ppmv}$, which is higher than Holocene values. The air yields show fluctuations of $20 \%$, which may be due to differences in the ice matrix, e.g. cracks through which gases escape during evacuation of the dry extraction vessel. The ${ }^{14} \mathrm{CO}$ and ${ }^{14} \mathrm{CO}_{2}$ concentrations have about 5\% errors, which are mainly due to background and fractionation corrections required in the AMS analysis of the small graphite samples (Alderliesten et al. 1998).

Table 1 Details about the samples of the Sbb52-core, yields, and concentrations

\begin{tabular}{ccccccc}
\hline $\begin{array}{c}\text { Depth } \\
(\mathrm{m})\end{array}$ & $\begin{array}{c}\text { Mass } \\
(\mathrm{kg})\end{array}$ & $\begin{array}{c}\text { Air yield }^{\mathrm{a}} \\
(\mathrm{mL} / \mathrm{kg})\end{array}$ & $\begin{array}{c}\mathrm{CO}_{2} \text { conc. }^{\mathrm{b}} \\
(\mathrm{ppmv})\end{array}$ & $\begin{array}{c}\mathrm{Mass}^{\mathrm{c}} \\
(\mu \mathrm{g} \mathrm{C})\end{array}$ & $\begin{array}{c}{ }^{14} \mathrm{CO}_{2} \text { conc. } \\
\left(\text { at. }^{-1}\right)\end{array}$ & $\begin{array}{c}{ }^{14} \mathrm{CO} \text { conc. } \\
\left(\text { at. }^{-1}\right)\end{array}$ \\
\hline 0.9 & 2.032 & 98 & 321 & 31 & - & $134 \pm 15$ \\
1.7 & 1.738 & 100 & 328 & 28 & $587 \pm 30$ & $156 \pm 17$ \\
2.7 & 2.058 & 99 & 319 & 32 & $530 \pm 27$ & $105 \pm 15$ \\
4.1 & 2.376 & 100 & 301 & 35 & $427 \pm 19$ & $62 \pm 12$ \\
8.4 & 1.986 & 119 & 296 & 34 & $453 \pm 23$ & $89 \pm 14$ \\
10.0 & 2.256 & 102 & 310 & 35 & $429 \pm 19$ & $67 \pm 12$ \\
16.5 & 2.246 & 123 & 300 & 40 & $429 \pm 18$ & $60 \pm 13$ \\
25.5 & 2.068 & 104 & 300 & 31 & $378 \pm 20$ & $40 \pm 13$ \\
38.0 & 2.173 & 100 & 299 & 32 & $337 \pm 18$ & $24 \pm 12$ \\
45.0 & 2.292 & 119 & 303 & 41 & $408 \pm 18$ & $36 \pm 12$ \\
\hline
\end{tabular}

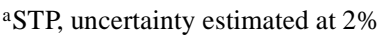

${ }^{b}$ Uncertainty estimated at $5 \%$

${ }^{\mathrm{c}}$ Mass of trapped $\mathrm{CO}_{2}$ 
Figure 1 shows the ${ }^{14} \mathrm{CO}$ and ${ }^{14} \mathrm{CO}_{2}$ concentrations as a function of depth. Both profiles, showing a steep decrease, have close correspondence in shape, even in individual data points, reflecting a constant ratio of the ${ }^{14} \mathrm{CO}$ to ${ }^{14} \mathrm{CO}_{2}$ components formed during ablation. The samples at $8.4,16.5$, and $45.0 \mathrm{~m}$, which have $20 \%$ higher air yield, show somewhat higher values in both the ${ }^{14} \mathrm{CO}$ to ${ }^{14} \mathrm{CO}_{2}$ profiles, but less than expected from a full correlation with the air yield. On the other hand, the low values for both the ${ }^{14} \mathrm{CO}$ and ${ }^{14} \mathrm{CO}_{2}$ concentrations of the 4.1-m sample do not show any fluctuation in air yield. Therefore, a correction to the concentrations based upon the air yield fluctuations does not seem to be straightforward.

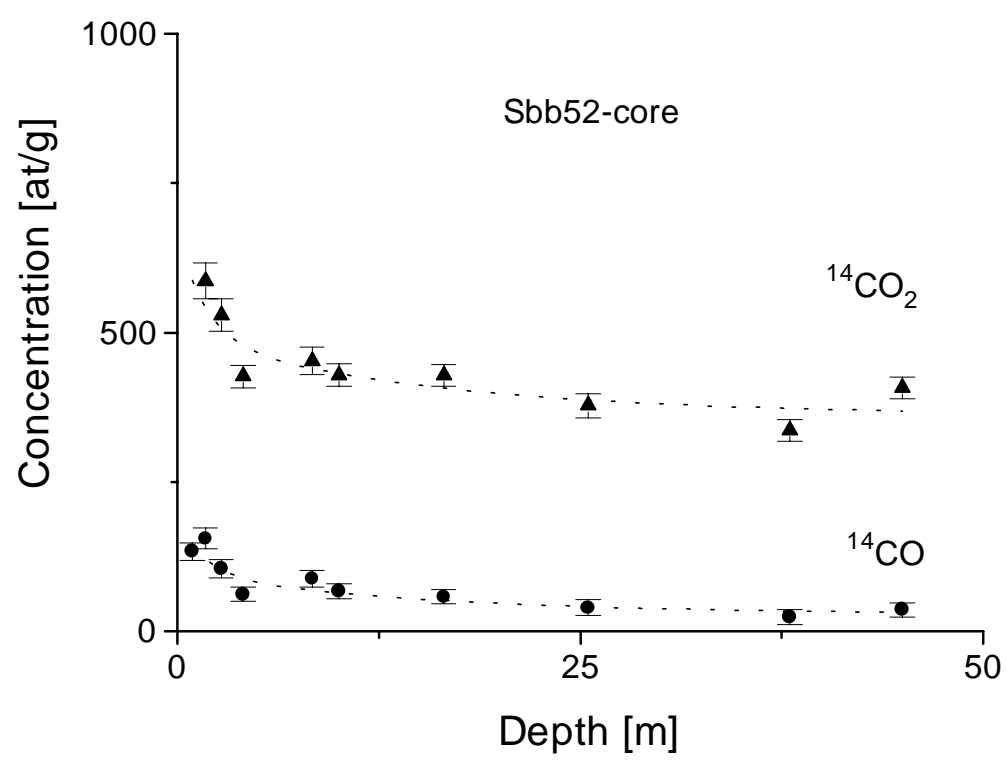

Figure 1 The concentration of ${ }^{14} \mathrm{C}$ as measured in the fractions ${ }^{14} \mathrm{CO}_{2}$ and ${ }^{14} \mathrm{CO}$ in a 52$\mathrm{m}$ ice core taken at an Antarctic blue ice field at Scharffenbergbotnen. The decrease in depth of both profiles shows the in-situ production in an ablation region. The dotted lines are fits to the data.

In-situ production of ${ }^{14} \mathrm{C}$ in ice takes place during accumulation, during transport and during ablation of the ice. The ${ }^{14} \mathrm{C}$ concentration comprises both the ${ }^{14} \mathrm{CO}_{2}$ and ${ }^{14} \mathrm{CO}$ fractions from either trapped component or from in situ production.

The ${ }^{14} \mathrm{C}$ concentration $C(h)$ in ablating ice can be described by a component $C^{a b l}(h)$ for in-situ ${ }^{14} \mathrm{C}$ production in the ablation region and by a component $C$ from other origin:

$$
C(h)=C^{a b l}(h)+C .
$$

The component $C^{a b l}(h)$ reflects the depth dependence from the (different) attenuation of the neutrons and muons from the cosmic rays. The concentration $C$ comprises the ${ }^{14} \mathrm{C}$ originating from the accumulation region in the form of trapped $\mathrm{CO}_{2}$ and in-situ ${ }^{14} \mathrm{C}$ in the firn. The concentration $C$ may have small depth but negligible dependence from the age difference in the core. The surface ice is expected to be the oldest as it has the longest pathway from the accumulation area. However, the time span of a few hundred years in the 52-m core-as estimated from the ablation rate-has a small effect on the ${ }^{14} \mathrm{C}$ concentration of the old ice (see below) with respect to the $5 \%$ uncertainty of the concentration. 
The depth dependence of the component $C^{a b l}(h)$ is given by the attenuation lengths of the neutron and captured muons (we neglect the contribution from fast muons as this is cannot be discriminated through the attenuation length longer than the length of the core; we assume its contribution contained in $C$ ). We use

$$
C^{a b l}(h)=A_{n} e^{-\frac{h}{\mu_{n}}}+A_{m} e^{-\frac{h}{\mu_{m}}}
$$

with

$$
A_{n}=\frac{P_{0 n}}{\lambda+\frac{a}{\mu_{n}}} \text { and } A_{m}=\frac{P_{0 m}}{\lambda+\frac{a}{\mu_{m}}}
$$

where $A_{n}$ and $A_{m}$ are the ${ }^{14} \mathrm{C}$ surface concentrations produced by neutrons and captured muons, respectively, as related to the ablation rate of a cm. $\mathrm{yr}^{-1}$ and the production rates $P_{n}$ and $P_{m}$ at.g ${ }^{-1} \cdot \mathrm{yr}^{-1}(\mathrm{Lal}$ et al. 1990), with $\lambda=\ln 2 / 5730 \mathrm{yr}^{-1}$ the decay constant and $\mu_{n}$ and $\mu_{m}$ the attenuation lengths with $\mu_{n}$ $=1.67 \mathrm{~m}$ (Lal et al. 1990) and $\mu_{m}=15.2 \mathrm{~m}$ (Bilokon et al. 1989).

We start the analysis with the fit of the ${ }^{14} \mathrm{CO}$ profile, because it is fully attributed to in-situ production and no complication occurs from a trapped component. We use the formulas (1.1) and (1.2) with CO-labeled coefficients. The fit to the ${ }^{14} \mathrm{CO}$-data, as shown in Figure 1, results in the values: $A^{C O}{ }_{n}=90 \pm 36, A^{C O}{ }_{m}=68 \pm 19$, and $C^{C O}=29 \pm 8$ at. $\mathrm{g}^{-1}$.

Subsequently, we fit the ${ }^{14} \mathrm{CO}_{2}$ profile, using the parameters found for the ${ }^{14} \mathrm{CO}$ profile and $A^{\mathrm{CO}}{ }_{n}=$ $r A^{C O}{ }_{n}$ and $A^{C O 2}{ }_{m}=r A^{C O}{ }_{m}$. We find $r=1.9 \pm 0.3$ and $C^{C O 2}=363 \pm 11$ at.g ${ }^{-1}$. For $A_{n}$, the sum of both components, we find $A_{n}=(1+r) A_{n}^{C O}=260 \pm 110$ at. ${ }^{-1}$ for the neutron component and similarly $A_{m}$ $=(1+r) A_{n}^{C O 2}=200 \pm 60$ at. $g^{-1}$ for the muon component. Using relation (1.3) for $A_{n}$, and the production rate by neutrons $P_{n}=67 \pm 4$ at. $\mathrm{g}^{-1}$ at altitude $1170 \mathrm{~m}$ (as derived from $P_{0 n}=15.7 \pm 0.7$ at. $\mathrm{g}^{-1} \cdot \mathrm{yr}^{-1}$ for quartz by Lifton et al. (2000), which reproduces the value deduced from the parametrization given by Lal 1991), we obtain an ablation rate $a=42 \pm 18 \mathrm{~cm} \cdot \mathrm{yr}^{-1}$ from the neutron component. Using the value for $A_{m}$ and the production rate by muons $P_{m}=5.3 \pm 0.5$ at $\mathrm{g}^{-1} \mathrm{yr}^{-1}$-as derived for ice from $P_{0 m}=3.7$ \pm 0.4 at $\mathrm{g}^{-1} \mathrm{yr}^{-1}$ in quartz (Heisinger 1998) by taking into account the differences for ${ }^{28} \mathrm{Si}$ and ${ }^{16} \mathrm{O}$ (von Egidy and Hartmann 1982) — we find an ablation rate $a=40 \pm 13 \mathrm{~cm} \cdot \mathrm{yr}^{-1}$ from the muon component.

Assuming in-situ production of ${ }^{14} \mathrm{CO}_{2}$ in the trapped $\mathrm{CO}_{2}$ is related to the asymptotic value of ${ }^{14} \mathrm{CO}$ by the ratio $r=1.9 \pm 0.3$ we estimate a total amount of $(1+r) C^{C O}=85 \pm 27$ at $^{-1}$. Correcting with this amount, we find $280 \pm 30$ at $\mathrm{g}^{-1}$ for the trapped ${ }^{14} \mathrm{CO}_{2}$. Compared to 970 at. ${ }^{-1}$ for modern $\mathrm{CO}_{2}$ trapped in ice we find an age of 10,300 $\pm 900 \mathrm{BP}$. The large uncertainty obtained in the age is due to the sum of the uncertainties from the fitting procedure. The correction for the in situ component in the trapped $\mathrm{CO}_{2}$ is based on the use of the ratio $r$ obtained from ablating ice. Whether this is allowed for in situ production from other origin, e.g. from the accumulation region, has not been proven. However, for rather small asymptotic ${ }^{14} \mathrm{CO}$ values the influence on this correction by the value of this ratio is rather small in comparison with the total uncertainty in the age.

\section{DISCUSSION}

The ablation rates $a=42 \pm 18 \mathrm{~cm} \cdot \mathrm{yr}^{-1}$ and $40 \pm 13 \mathrm{~cm} \cdot \mathrm{yr}^{-1}$ obtained from the in-situ production by neutrons and muons, respectively, are clearly higher that the $12 \pm 4 \mathrm{~cm} . \mathrm{yr}^{-1}$ ablation rate obtained from stake readings (Jonsson 1992). As the uncertainty in the production rates is only 10\%, this can- 
not explain the large discrepancy. Although the stake readings only probe the last 10 years, a large change in ablation rate would have been observed in the radionuclide concentrations. A possible explanation of the discrepancy can be an incomplete extraction of the dry extraction method. That would imply an extraction efficiency of only $30 \%$ of the in situ ${ }^{14} \mathrm{C}$ components.

The constant ratio for in-situ production of ${ }^{14} \mathrm{CO}_{2}$ and ${ }^{14} \mathrm{CO}$ over the time span of a few hundred years in the 52-m core suggests equilibrium may be reached in the oxidation of ${ }^{14} \mathrm{CO}$. Such equilibrium is not known and may depend on local ice conditions. Irradiation experiments in which ${ }^{11} \mathrm{C}$ was produced showed a $\mathrm{CO}_{2}$ fraction increasing with the applied dose (Lambrecht 1997).

The asymptotic value $C^{C O}$ of the ${ }^{14} \mathrm{CO}$ profile may be from in situ production from another origin. A part may originate from in-situ production by fast muons with a large attenuation length. Using $P_{f}=$ 0.210 at.g ${ }^{-1} . \mathrm{yr}^{-1}$ for ${ }^{14} \mathrm{C}$ production in ice by fast muons - as derived from $P_{f}=0.127$ at.g ${ }^{-1} \cdot \mathrm{yr}^{-1}$ in quartz measured by Heisinger (1998) — we estimate about half of the asymptotic value to be ascribed to the production by fast muons. The other half may originate from the accumulation region where it has been produced in the firn by neutrons. As the same decay constant applies to both the in-situ and the trapped fractions retained in the ice, the ratio of both fractions is independent on depth. Lal and Jull (1994) derived for the ratio of the in situ fraction over the trapped fraction $R=0.176 P_{0} / s$, with $P_{0}$ the production rate of ${ }^{14} \mathrm{C}$ and $s$ the accumulation rate of ice (Lal and Jull 1994). Using an average accumulation rate $s=6 \mathrm{~cm} . \mathrm{yr}^{-1}$ and $P_{0}=67 \pm 4$ at. $\mathrm{g}^{-1} \cdot \mathrm{yr}^{-1}$ we find $R=2.0$. Assuming $43 \pm 13$ at. $\mathrm{g}^{-1}$, being the half of the asymptotic in-situ production, originates from the accumulation region we find for the 52 -m core $R=0.45$, taking into account a 30\% extraction efficiency for the in situ components. That would mean a retainment of $23 \%$ in-situ ${ }^{14} \mathrm{C}$ of the firn in the ice, which is different from the observation by van der Kemp et al. (2000) who do not observe in situ production in accumulating ice.

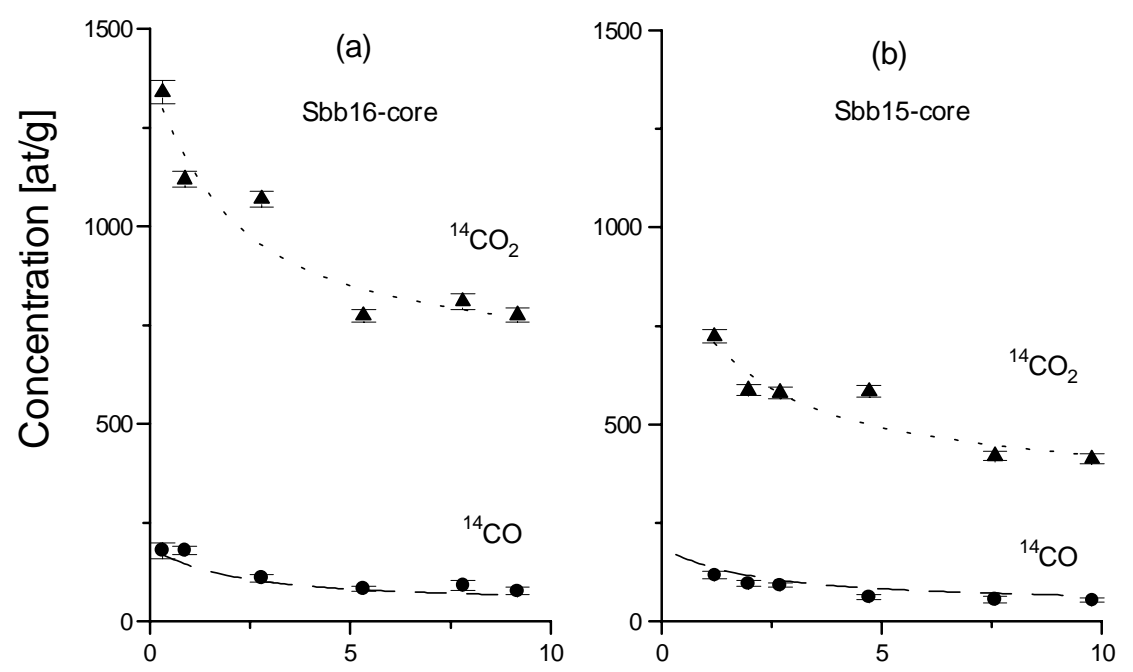

Figure 2 The ${ }^{14} \mathrm{C}$ data obtained by van Roijen et al. (1995) with 10-m ice cores of Scharffenbergbotnen in (a) Sbb-16, and (b) Sbb-15. The dashed lines in the ${ }^{14} \mathrm{CO}$ data have been taken from the 52-m core. The dotted lines are fits to the ${ }^{14} \mathrm{CO}_{2}$ data. 
The ${ }^{14} \mathrm{CO}$ profiles obtained by van Roijen et al. (1995) in shallow ice cores of 3 and $10 \mathrm{~m}$ from the same area are almost equal to the one obtained in the $52 \mathrm{~m}$ as is shown by the line through the data (Figure 2 above). This similarity indicates an equal extraction efficiency of ${ }^{14} \mathrm{CO}$ for the three cores. Using the same parametrization as used for the 52-m core we find $r=4.0 \pm 0.2,5.1 \pm 0.2$ and $C^{C O 2}$ $=277 \pm 16$ at. $\mathrm{g}^{-1}, 575 \pm 18$ at. $\mathrm{g}^{-1}$ for ${ }^{14} \mathrm{CO}_{2}$ profiles of the cores Sbb15 and Sbb16, respectively. Obviously, each core seems to have its own ratio $r$, which may reflect specific properties of the ice matrix. From the $r$-values we deduce the ablation rates $a=25 \pm 10$ and $20 \pm 8 \mathrm{~cm}$ from the neutron component and $a=24 \pm 7$ at. $\mathrm{g}^{-1}, 19 \pm 5$ at. $^{-1}$ for the muon component, respectively, which all are about a factor of two higher than the value from stake readings. From the $C^{\mathrm{CO}^{2}}$-values we obtain, similarly as above, the ratio of in-situ to trapped components $R=1.65$ and 0.66 , respectively, which differ from the $R=0.45$ obtained for the $52-\mathrm{m}$ core, and which may be due to variable wind ventilation in the accumulation area (Lal et al. 2000).

\section{CONCLUSIONS}

We observed in-situ ${ }^{14} \mathrm{C}$ over the whole depth range of the 52-m ice core, reflecting the production by neutrons in the first few meters and the production by captured muons at larger depth. We derive an ablation rate $a=42 \pm 18 \mathrm{~cm} . \mathrm{yr}^{-1}$ from the neutron component and $40 \pm 13 \mathrm{~cm} . \mathrm{yr}^{-1}$ from the muon component. Both values are about three times higher than the $a=12 \pm 4 \mathrm{~cm} . \mathrm{yr}^{-1}$ observed from stake readings (Jonsson 1992) and may be explained by 30\% efficiency in the dry extraction method for in-situ ${ }^{14} \mathrm{C}$.

We deduce an age of 10,300 $\pm 900 \mathrm{BP}$ for the 52-m ice core using a correction for in-situ-produced ${ }^{14} \mathrm{CO}_{2}$ in the trapped $\mathrm{CO}_{2}$ fraction, which depends on the choice for the ratio of in-situ production of ${ }^{14} \mathrm{CO}_{2}$ and ${ }^{14} \mathrm{CO}$ in ablating ice. Although a constant ratio has been observed in the ablation profiles of individual cores, the large variability among cores, make application of this ratio uncertain for in situ production from other origin, such as e.g. the accumulation region.

\section{ACKNOWLEDGMENTS}

We acknowledge the assistance of the logistic personnel during the expedition and the support by the technicians of the Accelerator Facility group and the Instrumental Physics group of the faculty. The work has been supported by the Netherlands Antarctic programme of the Netherlands Organisation fro Scientific Research (NWO).

\section{REFERENCES}

Alderliesten C, van der Borg K, de Jong AFM. 1997. Contamination and fractionation effects in AMS-measured ${ }^{14} \mathrm{C} /{ }^{14} \mathrm{C}$ and ${ }^{14} \mathrm{C} /{ }^{14} \mathrm{C}$ ratios of small samples. $R a$ diocarbon 40(2):215-21.

Andreé M, Moor E, Beer J, Oeschger H, Bonani G, Hoffman HJ, Morenzoni E, Nessi M, Suter M, Wölfli W. 1984. ${ }^{14} \mathrm{C}$ dating of polar ice. Nuclear Instruments and Methods in Physics Research B5: 385-8.

Bilokon H, Cini Castagnoli G, Castellina A, D'Ettore Piazolli B, Mannochini G, Meroni E, Picchi P, Vernetto S. 1989. Flux of vertical negative muons stopping at depths $0.35-1000 \mathrm{hg} / \mathrm{cm}^{2}$. Journal of Geophysics Research 94:145-52.

Brown ET, Bourles DL, Colin F, Raisbeck GM, Yiou F, Desgarceaux S. 1995. Evidence for muon-induced production of ${ }^{10} \mathrm{Be}$ in near-surface rocks from the
Congo. Geophysical Research Letters 22(6):703-6.

Cassidy W, Harvey R, Schutt J, Delisle G, Yanai K. 1992.

The meteorite collection sites of Antarctica. Meteoritics 27:490-525.

von Egidy T, Hartmann FJ. 1982. Average muonic Coulomb capture probabilities for 65 elements. Physical Review A26:2355-60.

Fireman EL, Norris TL. 1982. Ages and composition of gas trapped in Allan Hills and Byrd core ice. Earth and Planetary Science Letters 60:339-50.

Heisinger BP. 1998. Myonen-induzierte Production von Radionukliden [thesis]. München: Technical University. Unpublished.

Jonsson S. 1992. Local climate and mass balance of a blue-ice area in Western Dronning Maud Land, Antarctica. Zeitschrift für Gletscherkunde und Glaciolo- 
gie 26:11-29.

Jouzel J, Lorius C, Petit JR, Genthon C, Barkov NI, Kotyakov VM, Petrov VN. 1987. Vostok ice core: a continuous isotope temperature record over the last climatic cycle (160,000 years). Nature 329:403-8.

Jull AJT, Lal D, Donahue DJ, Mayewski P, Lorius C, Raynaud D, Petit JR. 1994. Measurements of cosmicray produced ${ }^{14} \mathrm{C}$ in firn and ice from Antarctica. $\mathrm{Nu}$ clear Instruments and Methods in Physics Research B92:326-30.

Kubik PW, Korschinek G, Nolte E, Ratzinger U, Ernst H, Teichmann S, Morinaga H. 1994. Accelerator mass spectrometry of ${ }^{36} \mathrm{Cl}$ in limestone and some paleontological samples using completely stripped ions. $\mathrm{Nu}$ clear Instruments and Methods in Physics Research B5:326-30.

Lal D, Peters B. 1967. Cosmic-ray produced radioactivity on the earth. In: Handbuch der physik. Volume 46/ 2. Berlin: Springer-Verlag. p 551-612.

Lal D, Nishiizumi K, Arnold JR. 1987. In situ cosmogenic ${ }^{14} \mathrm{C},{ }^{10} \mathrm{Be}$, and ${ }^{26} \mathrm{Al}$ for determining the net accumulation and ablation rates of ice sheets. Journal of Geophysical Research 92(B6):4947-52.

Lal D, Jull AJT, Donahue DJ, Burtner D, Nishiizumi. 1990. Polar ice ablation rates measured using in situ cosmogenic ${ }^{14} \mathrm{C}$. Nature 346:350-2.

Lal D. 1991. Cosmic ray labelling of erosion surfaces: in situ nuclide production rates and erosion models. Earth and Planetary Science Letters 104:424-39.

Lal D, Jull AJT, Donahue DJ, Burr GS, Deck B, Jouzel J, Steig E. 2000. The record of cosmogenic in-situ produced ${ }^{14} \mathrm{C}$ in Vostok and Taylor Dome ice samples: implications to strong role of wind ventilation processes. Journal of Geophysical Research Forthcoming.
Lambrecht RM. 1997. Evidence for insertion mode reaction of energetic carbon-11 with oxygen. Radiochimica Acta 77:37-43.

Lifton NA, Jull AJT, Quade J. 2000. A new extraction technique and production rate estimate for in situ cosmogenic ${ }^{14} \mathrm{C}$ in quartz. Radiocarbon. Submitted.

Raynaud D, Jouzel J, Barnola JM, Chappallaz J, Delmas RJ, Lorius C. 1993. The ice record of greenhouse gases. Science 259:926-34.

Schwander J, Stauffer B. 1984. Age differences between polar ice and the air trapped in the bubbles. Nature 311:45-7.

van der Borg K, Alderliesten C, Houston CM, de Jong AFM, van Zwol NA. 1987. Accelerator mass spectrometry with ${ }^{14} \mathrm{C}$ and ${ }^{10} \mathrm{Be}$ in Utrecht. Nuclear Instruments and Methods in Physics Research B29:143-5.

van der Borg K, Alderliesten C, de Jong AFM, van den Brink A, de Haas AP, Kersemaekers HJH, Raaymakers JEMJ. 1997. Precision and mass fractionation in ${ }^{14} \mathrm{C}$ analysis with AMS. Nuclear Instruments and Methods in Physics Research B123:97-101.

van der Kemp WJM, Alderliesten C, van der Borg K, Holmlund P, de Jong AFM, Karlöf L, Lamers RAN, Oerlemans J, Thomassen M, van der Wal RSW. 2000. Very little in-situ produced ${ }^{14} \mathrm{C}$ retained in accumulating Antarctic ice. Nuclear Instruments and Methods in Physics Research B172:632-6.

van Roijen JJ, van der Borg K, de Jong AFM, Oerlemans J. 1995. A correction for in-situ ${ }^{14} \mathrm{C}$ in Antarctic ice with ${ }^{14} \mathrm{CO}$. Radiocarbon 37(2):165-9.

van Roijen JJ. 1996. Determination of ages and specific mass balances from ${ }^{14} \mathrm{C}$ measurements on Antarctic surface ice [thesis]. Utrecht University. Unpublished. 